\title{
KRONIK
}

\section{Afetlerin Doğallığı Üzerine: Sosyal Bir Olgu Olarak Afetler ve Kırılganlık Sorunu}

Arş. Gör. İlker İnmez

Yaşadığımız gezegen var olduğu ilk günden beri doğası gereği çeşitli hareketlilikler sergilemektedir. Doğanın rutin işleyişi olarak ortaya çıkan depremler, seller, volkanik patlamalar ve firtınalar gibi doğa olaylarının canlıları tehdit etmesi de yeni değildir. Bununla birlikte, doğanın rutin işleyişinin afet şeklini alması yarattığımız insani sistemlerin bir sonucudur.

Afetler yarattıkları yıkıcı etkilerle bir taraftan da toplumların gelişme potansiyeline darbe vurmaktadır. Örneğin UNDP, doğal tehlikelerin tetiklediği afet kayıplarının, birçok toplumda kalkınma hedeflerine ulaşmada sorun yarattığını vurgulamaktadır. Altyapı sistemlerinin yıkılması, geçim erozyonu, ekosistem bütünlüğünün zarara uğraması ve mimari mirasın kaybı, hastalıklar ve ölümler gibi doğrudan etkilerle birlikte, afetler, finansal krizler, politik ve sosyal çatışmalar, hastalıklar ve çevresel bozulma gibi diğer sıkıntıları ve şokları da şiddetlendirmektedir. Bunun gibi afet kayıpları, yoksulluğu ve açlığı iyileştirme, eğitim sağlama, sağlık hizmetleri, güvenli yerleşim, içme suyu ve sıhhi tesisat sağlama ya da çevreyi koruma amaçlı sosyal yatırımları da engellemektedir (UNDP, 2004:9).

Türkiye, bulunduğu coğrafya itibariyle doğa olaylarının büyük canlılıklar sergilediği ülkelerden biridir. Aktif fay hattı üzerinde bulunan bir coğrafya olarak, seller, erozyon ve orman yangınları da sıklıkla yaşanmaktadır. Özellikle, tarihsel süreç içinde meydana gelen depremler yer yer uygarlıkların sona ermesine neden olan büyüklükte felaketlere yol açarak ayrı bir öneme kavuşmuştur. Ancak, yaşadığımız "doğal" afetleri jeolojik ya da atmosferik tetikleyicisine bağlı olarak tanımlamak afet olgusunu anlamamız açısından sorunlu olabilir. 
Tarihsel olarak baktığımızda, tüm dünyada afetlerin gerek şiddeti gerekse meydana geliş sıklıklarının artarak devam ettiği görülmektedir. ${ }^{1}$ Afetler bütün dünyada meydana gelmelerine karşın, özellikle gelişmekte olan ülkelerde trajik kayıplara sebep olmaktadır. Gerek gelişmiş gerekse gelişmekte olan ülkelerde meydana gelen afetlerin en yıkıcı maliyetlerine ise görece yoksul kesimler katlanmaktadir.

Afetler hakkında ortaya çıkan bu çarpıcı bilgiler, afetlerin doğallığını sorgulamamızı gerektirir. Kentleşme, yoksulluk, ekonomik ve sosyal yapının afetlerin yıkıcılığına yaptıkları katk1, konunun sosyal bir olgu olarak incelenmesinin gerektiğini açıkça göstermektedir.

$\mathrm{Bu}$ bağlamda afet çalışmaları 1950'li yıllardan başlayarak sosyal bilimlerin de ilgi alanına girmiş ve afetlerin salt bir "doğa işi” olmaktan ziyade, insanoğlunun kurduğu sosyal, politik, ekonomik ve çevresel sistemlerle de derin bağlarının olduğu iddiası giderek önem kazanmıştır. 1960'larda, doğal afetlerin yıkım gücünün, afet bölgelerindeki sosyal ve ekonomik karakteristiklerden kaynaklandığı yönünde fikirler öne sürülmüş ancak, 1970'lere kadar, ${ }^{2}$ doğal afet kırılganlığının (vulnerability) etmenleri olarak, ekonomik ve sosyal koşulların rolü kabul edilmemiştir. Doğal olayların, sadece kendi başına değil, afete eğilimli alanlardaki riskin karakteristiklerini de anlama yönündeki ilgi, birçok sosyal bilimciyi risk ve kırılganlık yönünde çalışmaya itmiştir (Alcantara-Ayala, 2002: 118). Bu anlayış, nihayet 1970'lerde genel bir kabule ulaşarak "kırılganlık" olgusunu ön plana çıkarmıştır. Afetler, artık bu genel kabule dayanarak, doğal sistem ile insani sistemler arasındaki çarpık ilişki olarak tanımlanmaya başlamış ve doğal olayların afetlere dönüşmesinin temel nedeninin toplumsal sistemlerdeki uyuşmazlıklar olduğu kabul edilmiştir.

Afetler konusundaki başlıca sorun, afetlerin tanımlanmasında yatmaktadır. Afetler, doğal tehlikelerin ve insani kırılganlıkların çakışmasının bir sonucudur. Tehlikeler, doğal, fiziksel ya da çevresel elementlerin zarar verme potansiyelini ifade etmektedir. Insani kirllganlıklar ise, fiziki yapılarla birlikte sosyal, ekonomik ve politik sistemlerden kaynaklı, potansiyel zarardan kaçınamama ve doğal tehlikelerin riskine açı olmayı ifade eder (Pelling, 2003: 5). Yani bir tehlikenin kendi başına gelişimi afet durumunu oluşturmaz. Afet durumu, insani sistemlerin ve bununla ilgili

\footnotetext{
${ }^{1}$ Tarihsel afet veri tabanı için bkz. EM-DAT, International Disaster Database, $<$ www.em-dat.be $>$

${ }^{2}$ Kırılganlık kavramının ilk ortaya çıkışı, O'Keefe, Westgate, ve Wisner'ın, doğal tehlikeler ve afetlerin meydana gelmesinde, sosyo-ekonomik koşulların belirleyiciliğini savundukları 1976'daki çalışmalarıdır. Bkz. (O’Keefe vd., 1976: 566567).
} 
kırılganlıkların (insani kırılganlıklar) yarattı̆̆ bir sonuçtur. Bu iki etki, zaman ve mekanda aynı koordinatlarda buluştuğunda doğal afetler meydana gelmektedir. (Alcantara-Ayala, 2002: 108).

Bir doğal tehlike, yaşamı ya da mülkiyeti tehdit eden jeofiziksel bir durumun doğal olarak ortaya çıkması demektir. Bu genellikle, atmosferdeki, hidrosferdeki, litosferdeki ya da biyosferdeki fenomenlerin değerlerindeki sapmalarla ortaya çıkan, ekstrem olayların riskini kapsar. Bir doğa olayı, insan yerleşimleri, toprak kullanımı ve sosyo-ekonomik organizasyon düzeniyle ilişkisi sonucu tehlike olarak tanımlanır. Bu ilişkiler, kolektif olarak insani sistemlerin doğal tehlike etkilerine karşı hassasiyetini ifade eden kırılganlık kavramını ortaya çıkarır. Kırılganlık, insanoğlunun doğal tehlikeleri algılaması, kontrolü ve adaptasyonu ile nitelendirilir.

Tehlikenin, teşhis edilebilen etki olasılığ çıkarır. Risk, veri alan ve referans zaman içinde belirli bir doğal tehlikeye bağlı olarak beklenen insani ve ekonomik kayıpların büyüklüğü ve olasılığı olarak tanımlanabilir. Risk, doğal tehlikeler ve kırılganlık olarak iki faktörün fonksiyonudur. İki öğe de, riskin oluşumu için gerekli koşulları sağlar. Örneğin, her y1l kaydedilen 100.000 deprem içinde sadece depreme dayanıklı altyapı sistemlerine sahip olmayan, yoğun oturulan alanlarda meydana gelen depremler afet haline gelir (Charveriat, 2000: 41).

Afeti sosyal fenomen olarak çalışanlar, kapitalizmle ilişkili olan belirli sosyal güçlerin de afet etkilerine karşı kırılganlık üretmekte olduğunu söylemişlerdir. Buna göre, ekonomik kalkınmayı ve büyümeyi destekleyen kurumlar da afet kırılganlığının artışında önemli rol oynamaktadır (Miller/Nigg, 1993: 3).

Kentsel alanlarda artan yoksulluk ve hızlı büyüme de kırılganlıkların artmasına sebep olan başlica faktörlerden biridir. Yirminci yüzyllda insan nüfusunun ve inşa ettiğimiz çevrenin aşırı derecede büyümesi, giderek daha çok sayıda insanın ve ekonomik faaliyetin dış değişimlere duyarlı hale gelmesi anlamına gelmektedir. İnsanların kıyılara ve kentlere göç etmesi de bir dizi doğal afete karşı duyarlılığı ve kırılganlığı arttırmaktadır (Abramovitz, 2001: 179). Örneğin, Latin Amerika son otuz yıl içerisinde hızlı ve kontrolsüz kentleşme yaşamıştır. Nüfusun $\% 75^{\prime}$ i şehirlerde yaşamaktadır ve bu şehirlerin temel altyapı sistemleri zayıf durumdadır. Bölgedeki şehirler yoğun yoksul nüfusu barındırmaktadır. Yoksulluk, doğası itibariyle insanları büyük risk altına sokmaktadır (Inter-American Development Bank, 2000: 6). Türkiye'de de özellikle 1980 sonrası hızlanan kentleşme süreci ile plansız yapılaşmaların artması ve yoksul köylü nüfusun şehirlere göç etmesi gecekondulaşma sürecini hızlandırarak güvensiz yaşam alanlarını oluşturmuştur. 
Bu bilgiler 1şığında, afetlerin ortaya çıkmasına neden olan temel sebebin ülkelere hâkim olan kalkınma paradigmaları olduğu açıktır. Albala-Bertrand, 26 farklı ülkedeki 28 olayı incelediği çalışmasında, afetlerin öncelikle bir kalkınma sorunu olduğunu fakat kalkınmak için bir sorun olmadığını söylemektedir. Kalkınma sorunu, kalkınmışlık seviyesi kadar kalkınma süreçlerini de işaret etmektedir. Sanayileşmiş zengin ülkelerin, afetler karşısında uğradığı kayıpların görece kontrol edilebilir ölçüde olması, kalkınmışlık seviyesine yani, kişi başına gelir, gelir dağılımı, kurumsallaşma, eğitim, sağlık, toplumsal dışlanmama v.s. derecelerine bağlıdır. Kalkınma süreçleri ise, ekonomik ve sosyal "modernizasyon" politikalarının yaratabileceği (yani, toprak mahrumiyeti, kültürel hakların kaybı v.s.) toplumsal grupların artan kırılganlığına işaret etmektedir (Albala-Bertrand, 1993: 202).

Uluslararası kamuoyunun artan afet durumları ve çalışmalarına ilgisi sonucu Birleşmiş Milletler 1990'lı yılları "Uluslararası Doğal Afetleri Azaltım Onyıll" olarak ilan etmiştir. Fakat Abromovitz'in (Abramovitz, 2001: 179) ifade ettiği gibi, 1990'lı yılların "Uluslararası Doğal Afetleri Azaltım Onyılı" ilan edilmesi ironik bir duruma yol açmıştır. İlan edilenin aksine 90'lar, maliyeti giderek artan seller, kasırgalar, depremler ve yangınlarla boğuşan dünyanın tarihine, Uluslararası Doğal Afetler Onyılı olarak geçmiştir. Bütün dünya, ekolojik olarak çevreye zarar veren uygulamalardan ve kendimizi felaketin yoluna koymamızdan dolayı yaşanan "doğal" afetlerin yol açtığı tahribattan payını almıştır. Birçok ekosistem doğal bozulmalara karşı duramayacak kadar güçsüz düşmekte ve parçalanmaktadır. Bu da, insan faaliyetleri yüzünden daha sert ve daha sık hale gelen "doğal olmayan" afetlere sahne hazırlamıştır. Ormanlara zarar vererek, nehirler üzerinde barajlar inşa ederek, sulak alanları doldurarak ve iklimin istikrarını bozarak karmaşık bir ekolojik güvenlik ağının bozmakta ve bu güvenlik ağının ne kadar değerli olduğu da ancak fark etmekteyiz.

$\mathrm{Bu}$ başarısız sonuç, muhtemelen afet durumları hakkında yapılan çalışmaların eksikliğinden çok sosyo-politik ve iktisadi sistemlere yapılan eleştirilerin göz ardı edilmesinden kaynaklanmaktadır. Gerek küresel bazda gezegene hakim paradigma, gerekse ulusal bazda insan ve doğayı hiçe sayan rekabetçi ve rantlarından vazgeçmek istemeyen sistemler konuya duyarsız kalmakta bir beis görmemektedir. İnsan, doğa ve topluma duyarlı ekolojik analizlerin göz ardı edilmesi, süregelen afet yıkımlarının sebebi olarak karşımıza çıkmaktadır. Benzer şekilde, uluslararası kuruluşlar tarafından bile, sürdürülebilir kalkınma anlayışının içinin boşaltılması bunun açık bir örneğidir. Türkiye açısından yaşanılan depremlerin yanında Karadeniz bölgesinde ve hatta büyük şehirlerde meydana gelen seller ve taşkınlar ölümlü sonuçlanmasına rağmen şehir planlamasına (ve planlamayı şekillendiren güç dengelerine) dair tartışmalar hükümet politikalarının gündemini oluşturmamaktadır. 
Çevresel risklerin ve kırılganlıkların ortaya çıkışı, toplumu ve çevreyi şekillendiren güç ilişkileri ile de yakından ilgilidir. Harvey'in ifade ettiği gibi, bütün ekolojik projeler (ve argümanlar) aynı zamanda, politik-ekonomik projelerdir (ve argümanlardır) ve aynı şekilde tersi de geçerlidir. Ekolojik argümanlar, hiçbir zaman sosyal olarak tarafsız değildir. ${ }^{3}$ Türkiye'de şehirlerin oluşumunu ve gelişimini belirleyen temel aktör olarak devletin, "ekonomik" getirileri çevresel ve toplumsal duyarlılıkların önüne koyması, şehirlerdeki bir diğer aktör olarak örneğin demokratik kitle örgütlerinin yönetime yeterince katılamamaları, afet eğilimli şehirlerin alt yapısını hazırlamaktadır. Genel olarak demokrasi algısının kısıtlı olması toplumsal kırılganlığı arttırmaya hizmet etmektedir. Böylece, afet eğilimli şehirlerin kurulmaya ve planlanmasına devam edilmesi bir sonraki kriz anına kadar yapay bir refahı yaşayan toplumu yaratmaktadır.

İnsan sistemlerinin kendisi, çalışma kavramı, çalışmanın sosyal dağılımı, üretim ilişkileri gibi unsurlar ekonomik-politik sistemlerin ortaya çıkardığı önemli değişimlere bağlıdır. $\mathrm{Bu}$ değişimler ve bunların doğal sistemle bağlantıları da, doğal tehlikelerin ve dolayısıyla afet dinamiklerinin temel kalıbı olarak hizmet etmektedir (Alcantara-Ayala, 2002: 108). Dolayısıyla gelişme planlarında, ekonominin sadece sermaye tarafının taleplerinin dikkate alındığ yapının sürdürülmesi, "büyümeci” politikaların refahı da sağlayacağı hatasını tekrarlamak doğal sistemlerin işleyişini görmezden gelmekle sonuçlanmaktadır.

"Doğal afetlerin" kronik ve katastrofik biçimlerini içeren çevresel riskler, kalkınma süreçlerinin bir sonucu olarak ortaya çıkarlar. Bundan öte, doğal afetler, hatalı ve açıkça sürdürülemez insan-doğa ilişkilerinin kapitalist (ve alternatif) gelişim modellerine dayanan eşitsizliklerin göstergesidir (Pelling, 2003: 6). Bu eşitsizlikler de açıkça, yoksulluk, yönetime katılamama, halk sağlığının gerilemesi, cinsiyet ve kültürel olarak sosyal dışlama gibi Türkiye'nin yaşadığı sorunları her seferinde karşımıza çıkarmaktadır.

Albala-Bertrand'ın ifade ettiği gibi “afet durumlarının uzun dönemli etkileri, afet kayıplarına değil süregelen sosyal dinamiklerle çakışmasına dayanmaktadır (Albala-Bertrand, 1993: 204).. Afetlerin gözlenen, politik, teknolojik, sosyal ya da iktisadi etkileri, öncelikle toplumların afet öncesi durumlarına göre açıklanır. Bu ayrıca etkilenen afet bölgeleri ile toplumun geri kalanı arasındaki iktisadi ve politik bağlantılara da dayanmaktadır. Afet tepkisi, normalde hükümetin ideoloji ve politikalarını yansıtmaktayken bir hükümetin kalkınma programı genellikle yeniden yapılanma planlarında gizlidir, bu nedenle, afetlerin kalkınma sonuçlarının çoğunu belirleyen, afetin kendisi değil

\footnotetext{
${ }^{3}$ Harvey, 1993: 25'ten aktaran Pelling, 2003: 4.
} 
hükümetin türüdür... Kırılganlık sorunu, koruyucu teknoloji ve mühendislik çalışmalarından çok, öncelikle bir sosyo-politik konudur. "

Afet İşleri Genel Müdürlüğü'nün Deprem Bölgeleri Haritası'na göre, Türkiye'nin \% 92'si deprem bölgesi içerisinde yer almasına ve nüfusun $\% 95$ 'i deprem tehlikesi altında yaşamasına karşın, halen büyük sanayi merkezlerinin \% 98'i ve barajların \% 93'ü deprem bölgesinde bulunması bu çarpık kalkınma anlayışının bir göstergesidir. Bir diğer örnek olarak, kıyı şeridine ekolojik yapıyı önemsemeden yapılan, Karadeniz sahil yolu Rize'yi vuran sel felaketinin sorumlusu olarak karşımıza çıkmıştır.

Türkiye'nin tehlikeli coğrafi yapısına karşın, afetler karşısında bu kadar hazırlıksız olması, çevre sorunlarına ve ekolojik duyarlılıklara sahip olmamasının bir sonucudur. Türkiye son olarak Van Depremini yaşamış olmakla birlikte, 1999'da tarihinin en büyük felaketlerinden Marmara Depremini tecrübe etmiş, ardından görece daha küçük çaplı, seller, orman yangınları, toprak kaymaları gibi afetleri yaşamıştır. Bu durumların analizi ve müdahalesinde yetkili çeşitli devlet kurumları ve sivil toplum kuruluşları bulunmasına rağmen, afetleri afet haline getiren kırılganlık olgusu bütünlüklü olarak tartışılmamıştır.

Genel olarak bakıldığında, afet azaltım sürecini etkileyen büyük sosyokültürel faktörler olarak; (1) inançlar ve kültürel uygulamalar, (2) politik ekonomi, (3) hükümet aktiviteleri ve diğer önemli kurumsal aktörler gösterilmektedir (Tierney, 1993: 16-19).

Afet konusunda yaşanan önemli bir sorun da afet sorununun belirttiğimiz çerçevede algılanmamasıdır. Afetlere nasıl tepki gösterildiği, esasen bu fenomenin nasıl tasavvur edildiğine bağlıdır. Örneğin, afetlerin "doğaüstü güçlerin cezalandırması" gibi kavramlarla algılanması, onlardan korunmak ya da etkilerini azaltmak için dinsel doğanın adımlarının atılması gerektiğini ifade etmektedir (UDEL, 2000: 2).

Temel olarak afet algılamasında üç farklı açıklama söz konusudur (Güvel, 2001: 14):

i. Afetlerin, Tanrı işi olarak (doğaüstü güçlerle) açıklanması.

ii. Afetlerin, "doğa işi”" olarak (doğal güçlerle) açıklanması.

iii. Afetlerin, "insan ve toplum işi”" olarak açılanması.

Açıklamalardan ilki, toplumun büyük ölçüde katıldığ i izlenimini uyandıran açıklamadır. 1999 depreminden sonra artan tepkilerle birlikte, devlet yönetimi bazında bu açıklamanın sürdürülebilirliği kalmamasına rağmen, toplumun büyük bir kısmının halen aynı görüşü paylaştığı fark edilebilmektedir. Bunun sebeplerini sadece dini inanışlara bağlamak analiz açısından sakıncalı olabilir. Zira ekonomik sebeplerle insanların güvenli inşa 
yapılarına erişiminin kısıtlı olması insanları bu kaderci algıya mahkum etmektedir. Bununla birlikte kaderci algılama ve boş vermişlik bireylerin yapı denetimlerini atlatma eğilimlerini kuvvetlendirmekte ve denetleyici kurumsal aktörler üzerinde bu konuda yeterince baskı oluşturmamalarına yol açmaktadır. Nihayet 1999 afetinden sonra, genel kabul gören "deprem öldürmez bina öldürür" algısına yönelmemiz önemli olmakla birlikte eksiktir. Zira insani kırılganlıkların analizi açısından, sosyo-politik ve ekonomik sistem eleştirilerini taşımamaktadır.

Türkiye'de afet durumlarının "insan ve toplum işi”" olarak algılanmaması kalkınma süreçlerinde kırılganlık unsurunu dışlamakla sonuçlanmaktadır. 1999 depreminin, ülke sanayisinin kalbini vurmasına rağmen halen deprem bölgelerine yeni sanayileşme planlarının yapılması, kalkınma planlarında insan ve doğa unsurunun yine göz ardı edildiğini ortaya koymaktadır. Bunun son örneği olarak, Sağlık Bakanlığı'nın uyarılarına ve demokratik kitle örgütlerinin itirazlarına rağmen Kocaeli şehir merkezine yapılmaya başlanan yeni Organize Sanayi Bölgesi'nde de görmekteyiz.

Albala-Bertrand'in işaret ettiği gibi, politik etki ve ekonomik alternatiflerin eksikliği, yoksulluk ve vatandaşlık haklarının kullandırılmaması kırsal veya kentsel alandaki kırılganlığın temeli olabilir (Albala-Bertrand, 2003: 77). Artan kırılganlık ve afet riski de, toplumlara kayıtsız gelişen küreselleşme sürecinin empoze ve talep ettiği toptan politika düzenlemelerine bağlanabilir. Bu kayıtsızlık, kurumsal yeniden yapılanmanın (yapısal düzenlemeler) hızlı ve derin bir biçimde ve özellikle de kırılgan insanların uyum sağlama kabiliyetinden daha hızlı olarak, empoze edilişindeki politika tutarsızlığında açıkça görülebilir. $\mathrm{Bu}$, insanları ve geçimlerini, güvensiz bir durumda bırakmakta ve emniyet boşluğu oluşturmaktadır.

Küresel ekonomiye eklemlenme çabaları, özellikle gelişmekte olan ülkelerde gelişmiş ülkeleri yakalama güdüsünü arttırarak, sosyal devletin yok oluşunu toplumsal olarak meşrulaştırmaktadır. Devlete, 1999 afetine kıyasla Van depreminde nispeten daha az sorumluluk atfedilmesi buna bağlanabilir. Deprem vergisi olarak adlandırılan 1999 sonrası çıkarılan ÖTV'nin amacı dışında kullanıldığının itirafı ve hatta konulma amacının reddedilmesi, bunun yanında güvenli olmayan yapıların sorumluluğunun sadece bireylerin üzerinde olduğunun ifade edilmesi, tüm itirazlara rağmen devlet kurumunun sahneden nasıl çekildiğinin göstergesidir. Bunun yanında, her afet sonrası halkın devlet yerine sivil yardım kuruluşlarına koşması da bu değişimin bir örneğidir. Devlet politikalarının, halkın afet karşısında güvenli yaşam alanlarına kavuşmasından çok "ekonomik büyüme"ye (çılgın projeler, duble yollar, nükleer santraller gibi) nasıl odaklandığını göstermektedir. Kısaca, yeni toprak rantlarının yaratılmasının güvenlikten önce geldiğini ortaya çıkarmıştır. 
Van depreminin ortaya çıkardığı bir diğer önemli kırılganlık da toplumun nası1 ikiye bölündüğünü göstermiştir. 1999 depremi sonrası gelen uluslararas1 yardımlarla, özellikle Türkiye ve Yunanistan ilişkilerinin nasıl onarıldığını, en azından yabancı düşmanlığının nasıl azaldığııı izlemiştik. Gerek afet bölgesindeki insanların etnik köken itibariyle devlet ayrımcılığına uğradığı algıs1, gerekse ülkenin bir kısmının (haber sunucularının ifadelerinde bile ortaya çıktığı üzere) afeti sevinçle karşılamaları toplumsal bölünmüşlügü ve sosyal dışlamanın ne boyutlarda olduğunu ortaya çıkardı. Yine benzer şekilde, devletin kurtarma çalışmalarında öncelikle sadece kendine yakın kabul ettiğgi ülke yardımlarını kabul etmesi yaşanılan zenofobi derecesine dikkatimizi çekmiş oldu.

Her ne kadar Van depreminde, afet sonrası çalışmalarda belediye yönetimi dışlanmış da olsa, devlet müdahalesi olarak ortaya çıkan tablonun bölgeye yapılan ayrımcılık olarak nitelenmesi doğru olmayacaktır. Bu bölgesel bir ayrımcılıktan çok, ülke çapında sosyal devletin yok oluşunu; afet azaltım ve önleme çalışmaları, afet planlanması ve müdahalesinden kendini soyutlamasının göstergesidir. Zira devlet politikası olarak her afet durumunda ortaya çıkan tablo aynıdır. Ancak bu çıkarım tabi ki, var olan toplumsal ayrışma ve nefretin, sosyal barış açısından onarılmasının zorunlu olduğu gerçeğini değiştirmez. Van depreminden iki ay önce, 17 Ağustos 1999 anmalarında, hükümetin afet acil eylem planı açıklamasına rağmen, aslında 12 yıldır gerekli adımların atılmadığını görmüş olduk. İstanbul'da afet durumları için ayrılan çadır alanlarının yapılaşmaya açıldığının ortaya çıkması da yine devletin bu konudaki duyarlılığını göstermiş oldu.

Sadece Van depremi özelinde değil, her afet durumunda yerel aktörlerin hem afet öncesi hem de afet sonrası çalışmalara, karar alma süreçlerine katılımının sağlanması önemlidir. Uzun dönemli sürdürülebilir bir kalkınma anlayışı, kırılganlıkların önlenmesi açısından bunu gerektirmektedir.

Demokrasi kavramı, yönetim açısından kurumların eleştiriye açıklığı ile toplumsal sistemleri ve dolayısıyla onu oluşturan aktörlerin işlevlerini ve hatalarını düzelten, yapıcı bir mekanizmayı da ifade etmektedir. Ancak 1999 depremi, Van depremi, yaşanan seller ve su baskınları gibi örneklerde de gördük ki kurumlara ve yetkililere yapılan eleştiriler bir duvardan seker gibi geri sekmiştir. Hiç bir yönetici bu güne kadar, afet sorumluluğunu kabul edip istifa etmemiştir. Dahası Van depremi sonrasında idarecileri protesto eden afetzedelere şiddetle müdahale edilerek belki de bir ilke imza atılmıştır.

Türkiye'de afet yönetimi anlayışı etkin proaktif bir yaklaşımdan çok tepkisel yaklaşıma dayanmaktadır. Afet yönetimi, toplumsal kırılganlıkların analiz edilerek afet eğilimli koşulların giderilmesinden çok, afet sonrası yardım ve kısa dönemli afet öncesi hazırlıklar sağlanması olarak algılanmaktadır. Oysa 
başarılı bir afet yönetimi için, etkili risk azaltım ve önleme stratejilerine ihtiyaç olmakla birlikte, afet sonrası sosyal ve ekonomik iyileşme süreci için de, uzun dönemli sürdürülebilir kalkınmayı hedefleyen, ekonomik ve sosyal risklerin azaltılmasına dayalı, disiplinler arası çalışmalar ile ve (halk sağlığı, çevresel bozulma, yoksulluk, yönetime katılma, sosyal dışlama, toplumsal cinsiyet gibi) kırılganlık unsurlarını hedefleyen kalkınma politikalarına ihtiyaç vardır.

İnsanlığın hatalarından ders çıkarmamakta ısrar edişi alışageldiğimiz bir durumdur. Ancak uygun politikalarla üstesinden gelinmesini de gerektirmektedir. Afet durumları karşısındaki tutumumuz, sürekli kırık bir sandalyeye oturmaya çalışan ve her düşüşünde parasal yardımların kendini kurtaracağını düşünen birinden öteye geçememektedir. Unutmamak gerekir ki, geçici refah dönemlerinin afetlerle sürekli kesintiye uğramasına şaşıran ve bundan ders çıkarmayan bir sosyo-ekonomik yapının hatalarının düzeltilmeden devam etmesini sağlamak, afetlerin önlenebilir bir durum olduğunu görmezden gelmektir.

\section{Kaynakça}

Albala-Bertrand, J.M., (1993), The Political Economy of Large Natural Disasters: With Special Reference to Developing Countries (Oxford: Calerendon Press).

Albala-Bertrand, J. M., (2003), "Urban Disasters and Globalization," KREIMER, Alcira/ ARNOLD, Margaret/CARLIN, Anne (eds.), Building Safer Cities: The Future of Disaster Risk (Washington D.C.: The World Bank).

Abramovitz, Janet, N., (2001), "Doğal Olmayan Felaketleri Önlemek," Dünyanın Durumu 2001, (İstanbul: TEMA Vakfı) (Çev: İdil Eser): 178-209.

Alcantara-Ayala, Irasema, (2002), "Geomorphology, Natural Hazards, Vulnerability and Prevention of Natural Disasters In Developing Countries," Geomorphology, 47: 107-124.

Güvel, Alper, (2001), Doğal Afetlerin Politik Ekonomisi: Doğal Riskler ve Afet Planlaması, (İstanbul: IMKB Yayını).

Charveriat, Celine, (2000), Natural Disasters in Latin America and Caribbean: An Overview of Risk (Washington D.C.: Inter-American Development Bank).

Harvey, David, (1993), "The Nature of the Environment: dialectics of social and environmental change," Milliband R. / Panitch, L., (eds), Real Problems False Solutions: Socialist Register (London: Merlin Press): 1-51. 
Inter-American Development Bank, (2000), Facing the Challenge of Natural Disasters in Latin America and Caribbean: An IDB Action Plan, <http://idbdocs.iadb.org/wsdocs/getdocument.aspx?docnum=823495>

Miller, Kristen/NIGG, Joanne M., (1993) "Event and Consequence Vulnerability: Effects on the Disaster Recovery Process," Paper Presented At The Annual Meeting of the Eastern Sociological Society, Boston, Ma., <http://www.udel.edu/drc/preliminary/217.pdf >.

EM-DAT, International Disaster Database, www.em-dat.be.

O'Keefe, P./ Westgate, K./ Wisner, B. , (1976), "Taking the naturalness out of natural disasters," Nature, 260: 566-567.

Pelling, Mark, (2003), The Vulnerability of Cities: Natural Disasters and Social Resilience (London: Routledge).

Tierney, Kathleen J., (1993) "Socioeconomic Aspects of Hazard Mitigation," <http://dspace.udel.edu:8080/dspace/handle/19716/577> : 16-19.

UDEL, (2000), Disaster Planning, Emergency Management and Civil Protection: The Historical Development.

UNDP, (2004), Reducing Disaster Risk (U.S.A.). 